\title{
The impact of governance quality on mortality rates in Sub Saharan Africa
}

\author{
Iheonu Chimere O. ${ }^{1}$, Agbutun Shedrach A. ${ }^{1}$, Omenihu Chinonyerem M. ${ }^{2}$, \\ Ihedimma Godfrey I. ${ }^{3}$, \& Osuagwu Vivian $\mathrm{N}^{1}{ }^{1}$ \\ ${ }^{1}$ Department of Economics, Faculty of the Social Sciences, University of Nigeria, \\ Nsukka, Nigeria \\ ${ }^{2}$ Department of Economics, Faculty of Social Sciences, University of Benin, \\ Benin-City, Nigeria \\ ${ }^{3}$ Department of Economics, Faculty of Arts, Management and Social Sciences, \\ Spiritan University, Nneochi, Abia State, Nigeria \\ Email: iheonuchimere@yahoo.com
}

\begin{abstract}
Background: The study examined the impact of governance quality on infant mortality, maternal mortality and adult female mortality in sub Saharan Africa.

Data Source and Methods: World Bank data covering 2002 to 2015 for 3I sub Saharan African countries were employed and analysed utilising the Driscoll and Kraay Fixed Effect Model.

Results: Improvements in regulatory quality and total governance reduces infant mortality by $0.144 \mathrm{I}$ and 0.0712 percentage points respectively. Improvements in the control of corruption, regulatory quality and total governance reduces maternal mortality by $0.0788,0.1324$ and 0.0654 percentage points respectively. Political stability reduces adult female mortality by 0.0485 percentage point.

Conclusion: There is need for the pursuit of efficient and speedy execution of sound private sector development policies in order to reduce infant and maternal mortality. Enhancing the fight against corruption aids maternal mortality reduction. Political stable environment should be prioritised to reduce adult female mortality. An overall improvement in the quality of governance reduces mortality rates in the region.
\end{abstract}

Keywords: Governance, Mortality, Sub Saharan Africa, Fixed Effect Model, Driscoll and Kraay.

\section{Introduction}

Though mortality rates across sub Saharan Africa has continued to drop over the years, the region still has a long way off in meeting the targets of the Sustainable Development Goals (SDGs) of the United Nations. Some of these targets relative to the discourse may include the target of 70 maternal deaths per 100,000 live birth by 2030 , reducing neonatal mortality to as low as 12 per 1,000 live births and reducing under- 5 mortality to as low as 25 per 1,000 live births. Many countries in the region have been plagued with high mortality rates. For example, Nigeria which has the biggest economy in sub Saharan Africa had a maternal mortality of 814 women per 100,000 live births in the year 2015, an infant mortality of 69 per 1,000 live births and an adult female mortality rate of 338 per 1,000 female adults. The Central African Republic which has one of the smallest economies in the region, under the same year had maternal mortality to be as high as 882 women per 100,000 live births, with an infant 4655 mortality of 92 per I,000 live births and an adult female mortality of 395 per I,000 female adults based on World Bank data.

Mortality rate in sub Saharan Africa remains the highest in the world according to the World Development Indicator, WDI (2017) of the World Bank. Figure I shows that maternal mortality in sub Saharan Africa has been the highest in the world within the period of 1990 and 2015. This also is observed to be double that of the world's average. Figure I also shows that Europe and Central Asia has the lowest rate of maternal mortality in the world. According to Mojekwu and lbekwe (20I2), a total of 99 percent of all maternal deaths occurs in developing countries with more than half of these deaths occurring in sub-Saharan Africa. Ujah, et al. (2005) acknowledge that developed countries account for 25 percent of females of reproductive age, however, they account for only I percent of maternal deaths worldwide.

http://aps.journals.ac.za 
Figure I: Maternal mortality ratio (modelled estimate, per 100,000 live birth), I99 I-20I5.

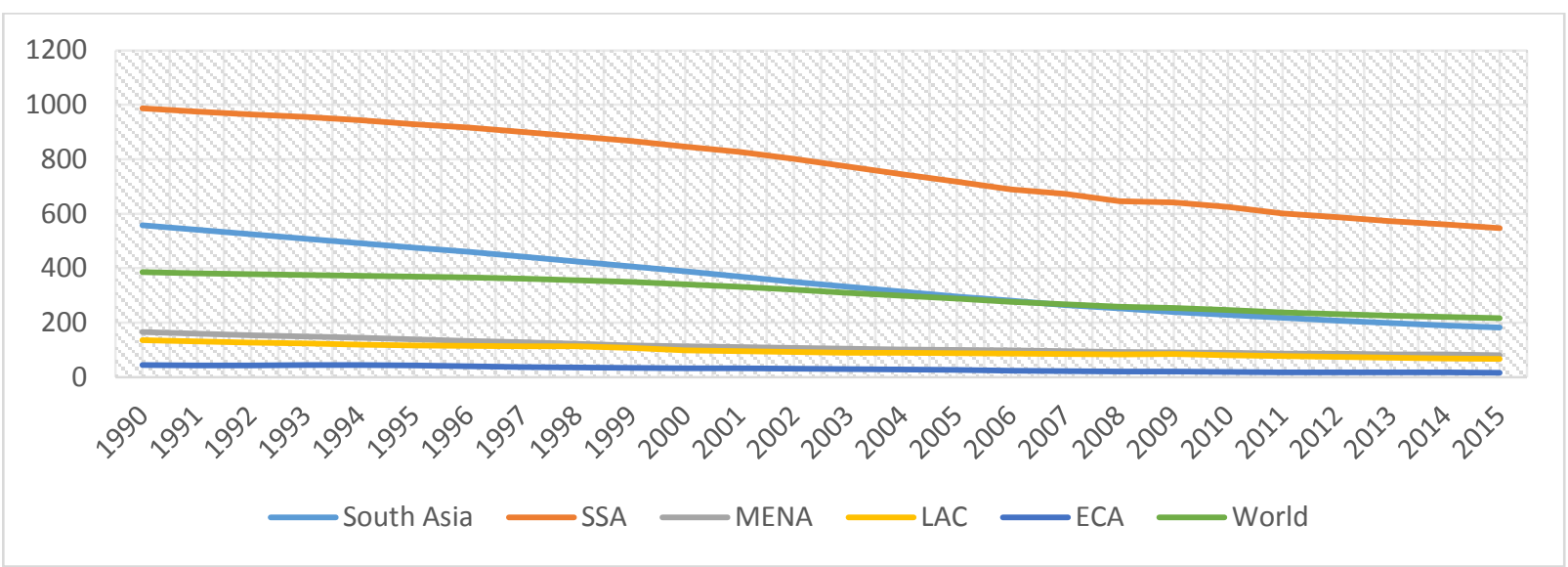

Source: Authors compilation from WDI (20I8).

Note: SSA denotes Sub Saharan Africa, MENA denotes Middle East and North Africa, LAC denotes Latin America and Caribbean, ECA denotes Europe and Central Asia.

Figure 2 also shows that the respective average rates for infant mortality, under-5 mortality and adult female mortality between the years 1990 to 2015 in sub Saharan Africa are still the highest in the world. Europe and Central Asia maintained the position with the lowest rates across the observed mean time. The high level of child mortality rates in sub Saharan Africa has been attributed to the prevalence of adult HIV and a low level of female education (Mogford,
2010), general deterioration in the quality of childcare (Opiyo and Sawhney, 20l4), low income per capita and low immunisation coverage (Hammer, Lensink and White, 2003) and then short birth intervals (Kaundjua, 20I3). Likewise, (Chisumpa, Odimegwu and De Wet, 2017) has attributed adult (female) mortality in sub Saharan Africa to poor health services.

Figure 2: Infant mortality, under-5 mortality and adult female mortality rate, 1990-2015, averaged.

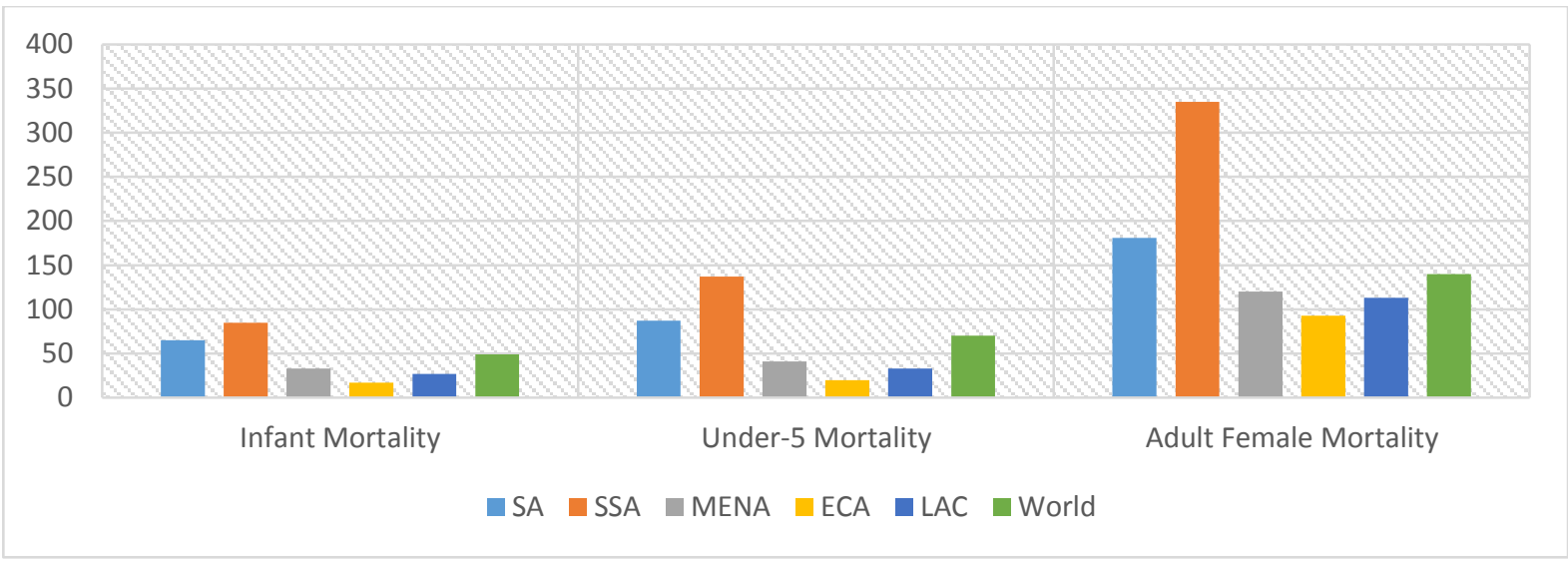

Source: Authors computation from WDI (2017)

Note: SA denotes South Asia, SSA denotes Sub Saharan Africa, MENA denotes Middle East and North Africa, LAC denotes Latin America and Caribbean, ECA denotes Europe and Central Asia.

The quality of governance in a society can influence various aspect of an economy in which mortality rates is a component. In fact, studies on the African continent has shown that governance is important in all spheres of economic development and progress (lheonu, 2019; Asongu et al., 2017; Asongu and Nwachukwu, 2016). Governance according to Fukuyama (20/3) is the ability of the government to make and enforce rules and to deliver services, irrespective of whether the government is democratic or not. It reflects how countries make decisions as well as providing sound policies to foster economic development and its ability to provide for her citizens. Good governance has been acknowledged by Kaufman, Kraay and Mastruzzi (2005) to foster overall economic development which ultimately leads to the reduction of mortality rates. By good governance, we mean the ability to 
control corruption, provide good policies for national development as well as providing a stable political environment. According to Asongu and Odhiambo (20I8), Africa's poverty tragedy of underdevelopment has been strongly linked to poor governance. It has also been verified that there is a strong causality between good governance and better development outcomes, such as higher per capita income, longer life expectancy and lower mortality rate (Emamgholipour and Asemane, 2016).

While there are studies on the determinants of mortality rates, especially maternal and child mortality, there have not been any extensive work to the best of our knowledge on how the quality of governance can influence mortality rates in sub Saharan Africa. It is on this premise the study seeks to investigate the impact of governance quality on mortality rates in the region, thus intensifying the literature on the relationship between governance and various dimensions of mortality with an aim of providing policy options targeted at reducing mortality rates. The study utilises an unbalanced panel data for 31 countries covering years 2002 to 2015 inclusive, and employing the Fixed Effect Model with Driscoll and Kraay (1998) standard errors which accounts for cross sectional dependence, serial correlation and groupwise heteroskedasticity. The study employs infant mortality per I,000 live births, maternal mortality per 100,000 live births and adult female mortality per I,000 adult females to capture mortality rates. Likewise, the study employs the control of corruption, political stability and regulatory quality to capture the quality of governance in the region. We also went further to create a composite index using the Principal Component Analysis to capture the joint impact of governance quality on these dimensions of mortality rates. The remainder of this research work includes a brief review of relevant literature, data and method utilised in the study, presentation and analysis of results, discussion of findings and conclusions with relevant policy recommendations.

\section{Literature review}

Reducing mortality, a major element of health outcomes is a key objective of any thoughtful government, as mortality reflects the level of economic development in a society. According to Deluna and Peralta (20/4), health outcomes signify how healthy an economy is, and the quality of healthcare in a country. Good health status across all dimensions is a vital form of human capital neccesary for economic growth and development. Omedi (2018) acknowledge that a high rate of early childhood mortality remains a threat to the socioeconomic development of any country.

The linkage in literature between governance quality and mortality rate is scarce, however, it has been acknowledged by Emamgholipour and Asemane (2016), that in nations with weak governance, public resources are wasted and are not converted into social investment. Emamgholipour and Asemane studied the effect of governance indicators on underfive mortality in 27 Organisation for Economic Cooperation and Development (OECD) countries from 1996 to 2012 employing the Generalised Method of Moments (GMM). The result reveals that an increase in governance quality reduces under-five mortality in OECD. Similar results were found by Lin et al. (20/4) in their study of governance influence on child mortality for 149 countries between 1996 to 2010 , while applying a semi-parametric generalised additive mixed model. The study utilised six dimensions of governance which includes political stability, control of corruption, government effectiveness, voice/accountability, regulatory quality and rule of law with result revealing that an improvement in governance reduces child mortality. The study concludes that the effect of governance on a country's population health is driven by government's response to her distribution of health-related programme resources, her response to her citizens' needs and the management of social and environmental conditions. Makuta and O'Hare (2015) studied whether the quality of governance has a modifying effect on the impact of public health spending on health outcomes in sub Saharan Africa. The study employed the Two Stage Least Squares Regression technique to account for endogeneity on a panel data of 43 countries for 1996 to 20II. The result found out that for countries with high governance quality, public health spending exerts greater negative influence on child mortality compared to countries with low governance quality. A study by Avendano (20/2) also showed that in OECD countries, economic factor such as inequality positively affect infant mortality, however, after controlling for country fixed effects, the relationship no longer holds.

Harrison (2009) observes that in Nigeria, a major way to reducting maternal mortality rate requires getting politics and government structures right. In India, Hamal et al. (2018) studied how social accountability mechanism contributes to better maternal health outcomes. The study utilised quantitative research through in-depth interviews and focus group discussions with actors of civil society and government health system. The result showed that social accountability mechanism influences the 
structural determinants - governance, policy, health beliefs, women's status of maternal health outcomes as well as the intermediary determinants - maternal healthcare behavior, social capital, availability, accessibility and quality of health service delivery system of maternal health outcomes. Shay and Say (2007) also revealed that countries with high maternal mortality have similar issues of high fertility and unplanned pregnancies, low availability of healthcare personnels and poor health infrastructure with limited resources. The study was examined between 1990 to 2005 across regions in the world.

Odhiambo, Wambugu and Kirita-Nganga (2015) studied the interaction of health expenditure and corruption and its effect on adult mortality in $4 \mathrm{I}$ sub Saharan African countries applying the Generalised Method of Moment. The result showed that while corruption positively influences the effectiveness of public health expenditure, it negatively influences private health expenditure. The result further revealed that regional variations exist within sub Saharan Africa with regards the effectiveness of both public and private health expenditure on adult mortality. Rebeira et al. (20/7) in their study of the impact of the rising income inequality in advanced countries on adult male and female mortality rates employed the pooled Ordinary Least Squares (OLS), the Fixed Effect Model and the dynamic OLS. Their study revealed that income inequality has an unfavourable consequence on adult male and female mortality.

This present study is particularly important as there have not been any study that examined how the various dimensions of governance quality influence various dimensions of mortality rates in sub saharan Africa. Likewise, the use of the PCA to capture the joint impact of governance on mortality rates in the region is novel. None of the previous studies have been able to examine the collective impact of governance on mortality rate in Sub Saharan Africa.

\section{Data and methods \\ Data}

The study employs annual data for 31 sub Saharan African countries from 2002 to 2015 which is based on data availability constraint. The variables employed in the study includes infant mortality per I,000 live births, maternal mortality per 100,000 live births (modelled estimate), adult female mortality per I,000 female adults, control of corruption, political stability, regulatory quality, consumer prices (annual $\%)$ which captures inflation, external health resource (\% of total expenditure on health), Physicians (per I,000 people) and HIV prevalence, total (\% of population ages 15-49). All the variables in the study covers 434 observations apart from physicians which has 172 observations for the countries across the time path of the study. This makes it imperative to utilise estimation techniques that account for unbalanced panel data. All the variables in our dataset are obtained from WDI (2017) of the World Bank except from the governance indicators which are derived from the World Governance Indicators, WGI (20I7). Countries employed in this study includes: Angola, Benin, Botswana, Burkina Faso, Cabo Verde, Cameroon, Central African Republic, Chad, Congo Republic, Cote d'Ivoire, Gambia, Ghana, GuineaBissau, Kenya, Liberia, Madagascar, Mali, Malawi, Mauritania, Mozambique, Niger, Nigeria, Rwanda, Senegal, Sierra Leone, South Africa, Sudan, Swaziland, Togo, Uganda and Zambia.

\section{Methods}

In analysing the impact of the quality of governance on mortality rates in sub Saharan Africa, the study utilises an unbalanced panel data set and the Fixed Effect Model with Driscoll and Kraay (1998) standard errors. A panel data is a combination of cross sections (countries) and time periods and a fixed effect entails controlling for country specific peculiarities that are constant overtime but vary between countries. The Driscoll and Kraay Fixed Effect Model correct standards errors for cross sectional dependence, serial correlation and heteroskedasticity utilising a non-parametric covariance matrix estimator. According to Hoechle (2007), with the presence of cross-sectional dependence, the Driscoll and Kraay Fixed Effect Model have small sample properties which are considerably better than other alternative covariance estimators.

Employing the Fixed Effect Model as our baseline model requires some basic tests for its suitability among other static panel models. Firstly, we run an F-test in order to confirm if there is omitted variable bias in our model. A less than 5 percent probability value would indicate that there are important country effects thus concluding that the Fixed Effect Model is appropriate. Secondly, we run a Hausman test to choose between the Fixed Effect Model and the Random Effect Model. The Hausman test allow us determine if the appropriate error terms are drawn from random distribution or are fixed (Baek and Yang, 2010). A probability value of less than 5 percent would indicate that the Fixed Effect Model is appropriate. We also test for serial correlation using the Wooldridge (2002) serial correlation test and heteroskedasticity applying the modified Wald test proposed by Lasker and King (1997). According to Amaz, Gaume and Lefevre (20I2), the null hypothesis denotes that the variance of the error is similar for all 
countries. The study as well tests for the presence of cross-sectional dependence employing the $x t c d 2$ command on Stata developed by Ditzen (2016) which can be applied to both balanced and unbalanced panel data set. The $x t c d 2$ tests a variable or residuals for weak cross-sectional dependence in panel models outlined by Pesaran (20I5). The tests have a null hypothesis of weak cross-sectional dependence of the variables or residuals and an alternate hypothesis of cross-sectional dependence. Baltagi, Kao and Peng (2016) describes cross sectional dependence as unknown common shocks, spatial effects or interactions within social networks.

We present an econometric fixed effect model where,

logmortality $_{i t}=\alpha_{1}$ Gov $_{i t}+\beta_{1} X_{i t}+\gamma_{i}+\mu_{i t}$

here, we capture mortality with three different measures and thus logmortality represents log of infant mortality rate per 1,000 live births, log of maternal mortality ratio per 100,000 live births (modelled estimate) and the log of adult female mortality rate per I,000 female adults. Gov is Governance quality represented by three dimensions of governance which includes the control of corruption, political stability/absence of violence and regulatory quality. WGI (2017) defined the

"control of corruption as the viewpoint of the degree to which public power is used for private gain, comprising both minor and grand forms of corruption as well the 'capture' of the state by elites and private interest".

Political stability captures the perception of the probability of political instability and/or politically motivated violence, including terrorism. Regulatory quality captures perceptions of the capability of the government to design and execute sound policies and rules that allow and promote private sector development. We also constructed a single index for governance from the three indices employed using the Principal Component Analysis so as to capture an overall impact of governance on mortality. The Principal Component Analysis involves reducing a set of strongly correlated variables into an uncorrelated set of small values known as Principal Components (Asongu et al., 2017), while the new variable remains an embodiment of the parent information in the data set (Tchamyou, 2017). In a Principal Component Analysis, we retain the factors that have an eigenvalue greater than one (Jollife, 2002).

In equation ( $\mathrm{I}), \mathrm{X}$ is the vector of control variables already defined in the data section and includes inflation rate, HIV prevalence, external resources for health and physicians.

Equation (I) can be re-specified as;

logmortality $_{i t}=\alpha_{1}$ Gov $_{i t}+\beta_{1}$ prices $_{i t}+\beta_{2}$ HIV $_{i t}+$

$\beta_{3}$ exrhealth $_{i t}+\beta_{4}$ physicians $i t+\gamma_{i}+\mu_{i t}$

$\gamma_{i}$ is the individual country fixed effect, $u$ is the error term, $i$ represents the cross-sectional index and $t$ is the time index.

\section{Results}

The summary statistics of the variables in the model was firstly carried out in order to describe our data. Table I shows that infant mortality has a mean value of 66 per 1,000 live birth in sub Saharan Africa, a maximum of 137 and a minimum of 18.9. On the average, maternal mortality has a value of 601.20 per 100,000 live births, with a maximum value of 2390 recorded by Sierra Leone in 2002 and a minimum value of 42 recorded by Cabo Verde in 2015. The low level of maternal mortality in Cabo Verde can be attributed to expanded health coverage across the Islands of the country. Adult female mortality can be seen in Table I to have an average value of 312.64 , a minimum value of 102.45 and a maximum value of 685. The minimum values of infant mortality and adult female mortality was also recorded in Cabo Verde which has also been attributed to expanded health coverage in the Islands.

Table I: Summary statistics of the variables in the dataset

\begin{tabular}{|c|c|c|c|c|}
\hline Variable & Mean & Minimum & Maximum & Observations \\
\hline Infant Mortality & 65.86 & 18.90 & 137 & 434 \\
\hline Maternal Mortality & 601.20 & 42 & 2390 & 434 \\
\hline $\begin{array}{ll}\text { Adult } & \text { Female } \\
\text { Mortality } & \end{array}$ & 312.64 & 102.45 & 685.03 & 434 \\
\hline $\begin{array}{l}\text { Control } \\
\text { Corruption }\end{array}$ & -0.62 & $-|.5|$ & 1.25 & 434 \\
\hline
\end{tabular}




\begin{tabular}{lcccc}
\hline Political Stability & -0.53 & -2.69 & 1.08 & 434 \\
Regulatory Quality & -0.58 & -1.88 & 0.79 & 434 \\
Inflation & 7.14 & -35.84 & 108.89 & 434 \\
$\begin{array}{l}\text { External Health } \\
\text { Resource }\end{array}$ & 22.13 & 0.32 & 73.78 & 434 \\
Physicians & -0.53 & -2.69 & 1.08 & 172 \\
HIV & 5.58 & 0.10 & 29.90 & 434
\end{tabular}

Source: Authors' Computation for data from WDI (2017) and WGI (2017).

The indicators of governance are also seen to have an average negative value. This reflects the poor quality of governance in the sub Saharan African region, where on the average, corruption persists, with low political stability in most of the countries in the region. Likewise, the government's in the region have not been able to implement sound policies that drives private sector development. However, some countries employed in the study exhibit good governance quality which is reflected by the positive maximum values of governance indicators in Table $I$.
Some of those countries include Botswana, Cabo Verde and South Africa.

On the average, the rate of inflation in the sub Saharan African region is of single digit with a value of 7.14, a minimum value of -35.84 and a maximum value of 108.89. External resource for health also has a mean value of 22.13 while the number of physicians per 1,000 people averages -0.53 , which is particularly worrisome as it reflects the poor state of the health sector in the region. The prevalence of HIV has a mean value of 5.58 in sub Saharan Africa.

Table 2: Correlation matrix of variables in the dataset

\begin{tabular}{|c|c|c|c|c|c|c|c|c|c|c|}
\hline & IM & $M M$ & AFM & $\mathrm{CC}$ & PS & RQ & INF & HIV & ERH & $\mathrm{PHY}$ \\
\hline IM & 1.00 & & & & & & & & & \\
\hline$M M$ & 0.85 & 1.00 & & & & & & & & \\
\hline AFM & 0.65 & 0.51 & 1.00 & & & & & & & \\
\hline $\mathrm{CC}$ & -0.64 & -0.71 & -0.31 & 1.00 & & & & & & \\
\hline PS & -0.42 & -0.52 & -0.15 & 0.73 & 1.00 & & & & & \\
\hline RQ & -0.54 & -0.55 & -0.11 & 0.79 & 0.62 & 1.00 & & & & \\
\hline INF & 0.01 & 0.06 & 0.06 & -0.04 & -0.13 & -0.07 & 1.00 & & & \\
\hline HIV & -0.07 & -0.18 & 0.57 & 0.34 & 0.35 & 0.48 & 0.06 & 1.00 & & \\
\hline ERH & 0.03 & 0.16 & 0.04 & -0.002 & 0.19 & -0.003 & 0.03 & 0.004 & 1.00 & \\
\hline PHY & -0.42 & -0.46 & -0.23 & 0.19 & -0.04 & 0.15 & 0.23 & 0.13 & -0.36 & 1.00 \\
\hline
\end{tabular}

Source: Authors' computation.

Note: IM is Infant Mortality Rate, MM is Maternal Mortality Rate, AFM is Adult Female Mortality Ratio, CC is Control of Corruption, PS is Political Stability, RQ is Regulatory Quality, INF is Inflation, HIV is HIV Prevalence, ERH is External Resources for Health, PHY is Number of Physicians.

Table 2 presents the correlation between the variables in the dataset. This is in a bid to address the issue of multicollinearity among the explanatory variables in the data before proceeding to estimation. Table 2 shows that the correlation between the regressors in the model is minimal and can be tolerated apart from the governance indicators which we would have to include in separate regressions.
However, table 2 shows that there is a negative correlation between the indicators of mortality rate and the indicators of governance quality.

Table 3 reveals the result of the cross-sectional dependence test employing the Pesaran (2015) procedure. As indicated in Table 3, the result reveals that all the variables employed in our econometric model exhibit cross sectional dependence in sub 
Saharan Africa. The probability values are less than conventional levels of statistical significance and hence we reject the null of weak cross-sectional dependence and fail to reject the alternative of crosssectional dependence.

Table 3: Pesaran (20I5) cross sectional dependence test

\begin{tabular}{lcc}
\hline Variables & Test Value & Probability \\
\hline Infant Mortality & $54.557^{* * * *}$ & 0.000 \\
Maternal Mortality & $80.005^{* * * *}$ & 0.000 \\
Adult Female Mortality & $80.108^{* * * *}$ & 0.000 \\
Control of Corruption & $41.573^{* * * *}$ & 0.000 \\
Political Stability & $17.314^{* * * *}$ & 0.000 \\
Regulatory Quality & $51.888^{* * * *}$ & 0.000 \\
Inflation & $54.557^{* * * *}$ & 0.000 \\
HIV & $79.442^{* * * *}$ & 0.000 \\
External Health Resource & $73.716^{* * * *}$ & 0.000 \\
Physicians & $21.782^{* * * *}$ & 0.000 \\
\hline
\end{tabular}

Source: Authors' computation.

Note: $* * *$ denotes statistical significance at $1 \%$.

This result suggests considerations for panel data technique that account for cross sectional dependence in order to make policy inferences as earlier proposed.

Table 4: Principal component analysis of governance indicators

\begin{tabular}{|c|c|c|c|c|c|c|}
\hline \multirow[t]{2}{*}{ Principal Component } & \multicolumn{3}{|c|}{ Component Matrix (Loadings) } & \multirow[t]{2}{*}{ Proportion } & \multirow[t]{2}{*}{ Cumulative } & \multirow[t]{2}{*}{ Eigenvalue } \\
\hline & $\mathrm{CC}$ & PS & RQ & & & \\
\hline First PC & 0.6006 & 0.5460 & 0.5840 & 0.7959 & 0.7959 & 2.3877 \\
\hline Second PC & -0.2549 & 0.8231 & -0.5074 & 0.1394 & 0.9353 & 0.4182 \\
\hline Third PC & -0.7578 & 0.1559 & 0.6336 & 0.0647 & 1.0000 & 0.1940 \\
\hline
\end{tabular}

Source: Authors computation.

Note: Number of Observations: 434. CC is corruption control; PS is political stability/absence of violence; RQ is regulatory quality. $\mathrm{PC}$ is principal component.

Constructing a composite index aimed at capturing the joint impact of the three dimensions of governance quality employed in the study on mortality rates, which we call 'total' governance, the result of the Principal Component Analysis in table 4 shows that the first principal component has a proportion of 0.7959 while the second and third principal components have a proportion of 0.1394 and 0.0647 respectively. Also, the first principal component has an eigenvalue of 2.3877 which is greater than one while the second and third principal component has an eigenvalue of 0.4182 and 0.1940 which is less than one. Therefore, constructing the new variable to capture total governance means that we retain the first principal component.

Table 5 presents the result on the impact of governance quality on infant mortality in sub Saharan Africa. We begin by highlighting the appropriateness of the Fixed Effect Model over the pooled OLS and the Random Effect Model.

Table 5: Governance quality and infant mortality in Sub Saharan Africa

\begin{tabular}{lllll}
\hline Model $(1)$ with & $\begin{array}{c}\text { Model (2) with } \\
\text { control of } \\
\text { corruption }\end{array}$ & political stability & $\begin{array}{c}\text { Model (3) with } \\
\text { regulatory } \\
\text { quality }\end{array}$ & $\begin{array}{c}\text { Model (4) with } \\
\text { total governance } \\
\text { index }\end{array}$ \\
\hline Constant & $3.7054^{* * *}$ & $3.6972^{* * *}$ & $3.6483^{* * * *}$ & $3.7311 * * *$ \\
& $(0.000)$ & $(0.000)$ & $(0.000)$ & $(0.000)$
\end{tabular}




\begin{tabular}{|c|c|c|c|c|}
\hline \multirow[t]{2}{*}{ Inflation } & $0.0026 * *$ & $0.0025 * *$ & $0.0023^{* *}$ & $0.0023^{* *}$ \\
\hline & $(0.034)$ & $(0.043)$ & $(0.040)$ & $(0.040)$ \\
\hline \multirow[t]{2}{*}{ HIV } & $0.0913^{* * * *}$ & $0.0947^{* * * *}$ & $0.0921^{* * * * *}$ & 0.0921 **** \\
\hline & $(0.000)$ & $(0.000)$ & $(0.000)$ & $(0.000)$ \\
\hline \multirow[t]{2}{*}{ External Health Resource } & $-0.0089 * * *$ & $-0.0089 * * *$ & $-0.0086 * * *$ & $-0.0086 * * *$ \\
\hline & $(0.002)$ & $(0.00 I)$ & $(0.002)$ & $(0.002)$ \\
\hline \multirow[t]{2}{*}{ Physicians } & $-0.1047 * * *$ & $-0.1037 * * *$ & $-0.1072 * * *$ & $-0.1072 * * *$ \\
\hline & $(0.000)$ & $(0.000)$ & $(0.000)$ & $(0.000)$ \\
\hline \multirow[t]{2}{*}{ Control of Corruption } & -0.0365 & & & \\
\hline & $(0.479)$ & & & \\
\hline \multirow[t]{2}{*}{ Political Stability } & & -0.0154 & & \\
\hline & & $(0.679)$ & & \\
\hline \multirow[t]{2}{*}{ Regulatory Quality } & & & $-0 .|44| * *$ & \\
\hline & & & $(0.024)$ & \\
\hline \multirow[t]{2}{*}{ Total Governance } & & & & $-0.07 \mid 2^{* *}$ \\
\hline & & & & $(0.024)$ \\
\hline F-stat Prob & 0.0000 & 0.0000 & 0.0000 & 0.0000 \\
\hline R-squared within & 0.4779 & 0.4768 & 0.4975 & 0.4975 \\
\hline F-test & 0.0000 & 0.0000 & 0.0000 & 0.0000 \\
\hline Hausman & 0.0000 & 0.0000 & 0.0000 & 0.0000 \\
\hline Wooldridge & 0.0000 & 0.0000 & 0.0000 & 0.0000 \\
\hline Wald & 0.0000 & 0.0000 & 0.0000 & 0.0000 \\
\hline
\end{tabular}

Source: Authors computation.

Note: Estimates are fixed effect models with Driscoll and Kraay standard errors. Probability values are in parenthesis. *** and ** represents statistical significance at I and 5 percent respectively. Diagnostic test results are probability values.

The result of the F-test shows that the Fixed Effect Model is more appropriate compared to the pooled OLS across all columns while the Hausman test shows that the Fixed Effect Model is a more appropriate choice model as opposed to the Random Effect Model across all columns. The Wooldridge test result across the columns show the presence of serial correlation and the Wald test also shows that there is heteroskedasticity. This completely justifies the use of the Fixed Effect Model with the Driscoll and Kraay standard errors. The econometric result reveals that the control of corruption and political stability have a negative yet statistically insignificant impact on infant mortality in sub Saharan Africa while regulatory quality and total governance have a negative and statistically significant impact on infant mortality in sub Saharan Africa. Regulatory quality however, reduces infant mortality by 0.144 I percentage point, while total governance reduces infant mortality by $0.07 / 2$ percentage point.

http://aps.journals.ac.za
The econometric result further reveals that inflation has a positive and significant impact on infant mortality in sub Saharan Africa. A percentage point increase in inflation leads to a more than 0.002 percentage point increase in infant mortality. HIV prevalence among adults can also be seen to positively and significantly lead to infant mortality. A percentage increase in HIV prevalence results to more than 0.09 percentage point increase in infant mortality in sub Saharan Africa. A percentage point increase in external health resource leads to about 0.009 percentage point decline in infant mortality in sub Saharan Africa. A unit increase in the number in Physicians in sub Saharan Africa also leads to about 0.104 percentage point decline in infant mortality.

Table 6 reveals the result of the impact of governance quality on maternal mortality in sub Saharan Africa. The result firstly shows that the Fixed Effect Model is more appropriate compared to the pooled OLS as adjudged by the F-test and the 
Random Effect Model as adjudged by the Hausman test. The Wooldridge test for serial correlation also shows that the error terms in our models across all columns suffer from serial correlation, while the modified Wald test result across the columns shows that the models suffer from heteroskedasticity.

Table 6: Governance quality and maternal mortality in Sub Saharan Africa

\begin{tabular}{|c|c|c|c|c|}
\hline & $\begin{array}{l}\text { Model (I) with } \\
\text { control of } \\
\text { corruption }\end{array}$ & $\begin{array}{l}\text { Model (2) with } \\
\text { political stability }\end{array}$ & $\begin{array}{c}\text { Model (3) with } \\
\text { regulatory } \\
\text { quality }\end{array}$ & $\begin{array}{c}\text { Model (4) with } \\
\text { total governance } \\
\text { index }\end{array}$ \\
\hline Constant & $\begin{array}{l}5.3432 * * * \\
(0.000)\end{array}$ & $\begin{array}{l}5.3268^{* * * *} \\
(0.000)\end{array}$ & $\begin{array}{l}5.2857^{* * * *} \\
(0.000)\end{array}$ & $\begin{array}{l}5.3618^{* * * *} \\
(0.000)\end{array}$ \\
\hline Inflation & $\begin{array}{l}0.0041^{\text {***** }} \\
(0.006)\end{array}$ & $\begin{array}{l}0.0039 \text { **** } \\
(0.010)\end{array}$ & $\begin{array}{l}0.0038^{* * * *} \\
(0.007)\end{array}$ & $\begin{array}{l}0.0038^{* * * *} \\
(0.007)\end{array}$ \\
\hline HIV & $\begin{array}{l}0.1425 \text { **** } \\
(0.000)\end{array}$ & $\begin{array}{l}0.1499 * * * \\
(0.000)\end{array}$ & $\begin{array}{l}0.1480 * * * \\
(0.000)\end{array}$ & $\begin{array}{l}0.1480 * * * \\
(0.000)\end{array}$ \\
\hline External Health Resource & $\begin{array}{l}-0.0059 * * * \\
(0.001)\end{array}$ & $\begin{array}{l}-0.0059 * * * \\
(0.000)\end{array}$ & $\begin{array}{l}-0.0058^{* * * *} \\
(0.001)\end{array}$ & $\begin{array}{l}-0.0058^{* * * *} \\
(0.001)\end{array}$ \\
\hline Physicians & $\begin{array}{l}-0.1517^{* * * *} \\
(0.000)\end{array}$ & $\begin{array}{l}-0.1494 * * * \\
(0.000)\end{array}$ & $\begin{array}{l}-0.1522 * * * * \\
(0.000)\end{array}$ & $\begin{array}{l}-0.1522 * * * \\
(0.000)\end{array}$ \\
\hline Control of Corruption & $\begin{array}{l}-0.0788^{*} \\
(0.100)\end{array}$ & & & \\
\hline Political Stability & & $\begin{array}{l}-0.0278 \\
(0.384)\end{array}$ & & \\
\hline Regulatory Quality & & & $\begin{array}{l}-0.1324 * * * \\
(0.005)\end{array}$ & \\
\hline Total Governance & & & & $\begin{array}{l}-0.0654^{* * * *} \\
(0.005)\end{array}$ \\
\hline F-stat Prob & 0.0000 & 0.0000 & 0.0000 & 0.0000 \\
\hline R-squared within & 0.6223 & 0.6164 & 0.6318 & 0.6318 \\
\hline F-test & 0.0000 & 0.0000 & 0.0000 & 0.0000 \\
\hline Hausman & 0.0000 & 0.0000 & 0.0000 & 0.0000 \\
\hline Wooldridge & 0.0000 & 0.0000 & 0.0000 & 0.0000 \\
\hline Wald & 0.0000 & 0.0000 & 0.0000 & 0.0000 \\
\hline
\end{tabular}

Source: Authors computation.

Note: Estimates are fixed effect models with Driscoll and Kraay Standard Errors. Probability values are in parenthesis. *** and * denotes statistical significance at I and 10 percent respectively. Diagnostic test results are probability values.

The econometric result as contained therein reveals that the control of corruption has a negative and statistically significant impact on maternal mortality in sub Saharan Africa. The control of corruption reduces maternal mortality by 0.0788 percentage point. Political stability can also be seen to have a negative impact on maternal mortality but not at any conventional statistically significant level, thus 
regarded as insignificant. However, regulatory quality has a negative and statistically significant impact on maternal mortality in sub Saharan Africa. The result shows that regulatory quality reduces maternal mortality by 0.1324 percentage point. The result further reveals that total governance has a negative and statistically significant impact on maternal mortality in sub Saharan Africa. Total governance reduces maternal mortality by 0.0654 percentage point.

More result from Table 6 reveals that inflation has a positive and significant impact on maternal mortality. A percentage point increase in inflation rate leads to about 0.0038 percentage point increase in maternal mortality across all columns. Also, HIV prevalence among adults has a positive and significant impact on maternal mortality. A percentage point increase in HIV prevalence leads to about 0.14 percentage point increase in maternal mortality in sub Saharan Africa. External resources for health and the number of Physicians have a negative and significant impact on maternal mortality in sub Saharan Africa. A percentage point increase in external health resources and the number of physicians reduces maternal mortality by about 0.0058 percentage point and 0.15 percentage point respectively.

Table 7 presents the result of the impact of governance quality on adult female mortality rate in sub Saharan Africa. The result firstly reveals the preference for the Fixed Effect Model among other panel linear models. The result of the F-test denotes that the Fixed Effect Model is more appropriate compared to the pooled OLS and the result of the Hausman test shows that the Fixed Effect Model is also more appropriate compared to the Random Effect Model. Secondly, the result of the Wooldridge test and the modified Wald test shows the presence of serial correlation and heteroskedasticity respectively, which justifies employing the Fixed Effect Model with Driscoll and Kraay standard error.

Table 7: Governance quality and adult female mortality in Sub Saharan Africa

\begin{tabular}{|c|c|c|c|c|}
\hline & $\begin{array}{c}\text { Model (I) with } \\
\text { control of } \\
\text { corruption }\end{array}$ & $\begin{array}{l}\text { Model (2) with } \\
\text { political stability }\end{array}$ & $\begin{array}{c}\text { Model (3) with } \\
\text { regulatory } \\
\text { quality }\end{array}$ & $\begin{array}{c}\text { Model (4) with } \\
\text { total governance } \\
\text { index }\end{array}$ \\
\hline Constant & $\begin{array}{l}4.9034 * * * \\
(0.000)\end{array}$ & $\begin{array}{l}4.8918^{* * * *} \\
(0.000)\end{array}$ & $\begin{array}{l}4.9007^{* * * *} \\
(0.000)\end{array}$ & $\begin{array}{l}4.9076^{* * * *} \\
(0.000)\end{array}$ \\
\hline Inflation & $\begin{array}{l}0.0028^{* * * *} \\
(0.009)\end{array}$ & $\begin{array}{l}0.0027 * * \\
(0.014)\end{array}$ & $\begin{array}{l}0.0028 * * * \\
(0.007)\end{array}$ & $\begin{array}{l}0.0028^{* * * *} \\
(0.007)\end{array}$ \\
\hline HIV & $\begin{array}{l}0.1456 * * * \\
(0.000)\end{array}$ & $\begin{array}{l}0.1423 * * * * \\
(0.000)\end{array}$ & $\begin{array}{l}0.1438^{* * * *} \\
(0.000)\end{array}$ & $\begin{array}{l}0.1438^{* * * *} \\
(0.000)\end{array}$ \\
\hline External Health Resource & $\begin{array}{l}-0.0048^{* * * *} \\
(0.002)\end{array}$ & $\begin{array}{l}-0.0045^{* * * *} \\
(0.001)\end{array}$ & $\begin{array}{l}-0.0048^{* * * *} \\
(0.002)\end{array}$ & $\begin{array}{l}-0.0048^{* * * *} \\
(0.002)\end{array}$ \\
\hline Physicians & $\begin{array}{l}-0.0897^{* * * *} \\
(0.000)\end{array}$ & $\begin{array}{l}-0.092 I^{* * * *} \\
(0.000)\end{array}$ & $\begin{array}{l}-0.0907^{* * *} \\
(0.000)\end{array}$ & $\begin{array}{l}-0.0907^{* * * *} \\
(0.000)\end{array}$ \\
\hline
\end{tabular}

Control of Corruption

0.0149

Political Stability

Regulatory Quality

$-0.0119$

Total Governance 


\begin{tabular}{|c|c|c|c|c|}
\hline R-squared within & 0.5733 & 0.5823 & 0.5732 & 0.5732 \\
\hline F-test & 0.0000 & 0.0000 & 0.0000 & 0.0000 \\
\hline Hausman & 0.0000 & 0.0000 & 0.0000 & 0.0000 \\
\hline Wooldridge & 0.0000 & 0.0000 & 0.0000 & 0.0000 \\
\hline Wald & 0.0000 & 0.0000 & 0.0000 & 0.0000 \\
\hline
\end{tabular}

Source: Authors computation.

Note: Estimates are fixed effect models with Driscoll and Kraay Standard Errors. Probability values are in parenthesis. **** and ${ }^{* *}$ denotes statistical significance at I and 5 percent respectively. Diagnostic test results are probability values.

The econometric result shows that the control of corruption positively but insignificantly influences adult female mortality rate in sub Saharan Africa. Also, regulatory quality and total governance have a negative yet insignificant impact on adult female mortality rate in sub Saharan Africa while political stability has a negative and significant impact on adult female mortality rate in sub Saharan Africa. Political stability reduces adult female mortality rate by 0.0485 percentage point.

Furthermore, inflation has a positive and statistically significant impact on adult female mortality rate in sub Saharan Africa. A percentage increase in inflation leads to about 0.0027 percentage point increase adult female mortality rate. HIV prevalence also have a positive and significant impact on adult female mortality rate. The result shows that a percentage increase in HIV prevalence leads to about 0.14 percentage point increase in adult female mortality. However, external resources on health and the number of physicians both have negative and statistically significant impact on adult female mortality in sub Saharan Africa. A percentage point increase in external resources for health leads to about 0.0045 percentage point decrease in adult female mortality rate while a percentage point increase in the number of physicians leads to a 0.09 percentage point decrease in adult female mortality rate.

\section{Discussion}

The need to reduce maternal, infant and adult female mortality continues to be of high and urgent priority in international development because these groups in the society tend to be the most vulnerable. Hence, we undertook this study to discover the role of governance on the reduction of these dimensions of mortality in sub Saharan Africa, as the region pursues the SDGs with the 2030 vision in view.

First, the study reveal that the control of corruption has a negative and insignificant impact on infant mortality but a negative and significant impact on maternal mortality. This result suggests that controlling corruption would result to a decline in 4665 infant mortality trivially however, would be pivotal in reducing maternal mortality rate in sub Saharan Africa. This result connotes that channelling funds into the health sector and other sectors in the economy without its misappropriation would aid in the reduction of maternal mortality. Ranking from Transparency International (2017) shows that 22 African countries appear amongst the 40 most corrupt countries in the world. Corruption can as well lead to poor coverage and inequality in access to healthcare. Jose and Saidou (2008) also found that corruption is a major problem of healthcare availability in Africa. This then means that if African countries, and in particular, sub Saharan Africa can control corruption, it would significantly lead to the decline in maternal mortality. Regulatory quality which entails the ability of the government to design policy which promotes private sector development shows a negative and significant relationship with infant and maternal mortality rates. This means that if the private sector is encouraged to participate in economic activities, infant and maternal mortality rates would be reduced. The increase in private sector participation in economic activities improves employment, and one of the major determinants of health is employment status. The lack of employment deprives citizens of the ability to access quality healthcare and nutrition due to lack of income which increases the likelihood of infant mortality.

The result also reveals that an improvement in total governance reduces infant and maternal mortality. This shows that if sub Saharan African countries continue to build upon sound policy formulation, planning and execution, putting measures to control corruption and public fund misappropriation, ensuring political stability especially in terms of creating a peaceful environment to foster domestic and private sector investment, infant and maternal mortality will reduce. Also, a stable political environment will reduce adult female mortality rate in sub Saharan Africa.

The result further reveals that inflation has a significant positive effect on the three dimensions of mortality rate in sub Saharan Africa. From theory, it is http://aps.journals.ac.za 
known that an increase in the rate of inflation comes with a corresponding decrease in the general welfare of the citizenry and further moves individuals below the poverty line. Inflation reduces the amount of goods and services which individuals can consume due to increase in prices. With this, it reduces the chances of individuals in the region in accessing and paying for quality healthcare which they require for healthy living, thus, being a critical aspect of welfare. This finding is in consonance with that of Richardo and Rocheteau (2005) in their study on inflation, output and welfare, where they found that inflation reduces consumer welfare, which reduce their chances of staying alive. Also, Grossman (1972) in his basic model of demand for health treats consumption of market goods as critical components in the production of health, which high inflation rate tend to affect negatively in the region.

Furthermore, findings from the study show that HIV is a cause of mortality rates in the region. This is apriori as the region has the highest rate of transmittion compared to other regions in the world. According to UNAIDS (2018), 940,000 deaths were attributed globally to HIV alone, and sub Saharan Africa account for estimated 66 percent of people living with HIV. This shows that as a matter of urgency, governments of the region should make managing the disease a top priority. Although the disease is manageable, it still remains a major cause of mortality in the region due to the high cost of its management. The UNAIDS further revealed that although four out of five people living with HIV know their status and are receiving treatment, $8 \mathrm{I}$ percent of them were virally suppressed, hence leading to mortality. The results show that HIV is a significant cause of infant mortality in the region, this is justified due to the nature of healthcare and health facilities in the region as the chances of an infant surviving is very minimal after mother to child transmission of the disease.

External health resource reveals a negative and significant relationship with mortality rates. This shows that external health resources can play a very important role in achieving better health status and consequently reducing mortality in the region, thus, achieving the objectives of the SDGs. These resources which come into the region in form of remittances, grants, medical outreaches and so on, are very important towards achieving universal health coverage especially with the high unemployment rates, increased population growth rates and inequality. The inflow and utilization of these resources is necessary and highly desirable. Also, physicians per 1000 of the population showed a significantly inverse relationship with the mortality rates. This reveals that proper training and increase in the supply of physicians is very paramount to the reduction of mortality in the region. With the region facing problems of poor healthcare delivery and high economic losses due to medical tourism, investing in local manpower becomes necessary. If the region is to reduce the rate of mortality, it must begin to invest locally on its health industry in order to increase health coverage and improve health outcomes.

\section{Conclusion and recommendations}

This study examined the impact of governance quality on mortality rates in sub Saharan Africa applying the Fixed Effect Model with Driscoll and Kraay standard errors, which accounts for cross sectional dependence, serial correlation and groupwise heteroskedasticity. The study employed 31 sub Saharan African countries between the years 2002 to 2015 utilising three indicators of governance and creating a composite index to capture an overall effect of governance on mortality rates in sub Saharan Africa. Infant mortality, maternal mortality and adult female mortality were employed to capture mortality rates. The result reveals that (I) improving regulatory quality and total governance reduces infant mortality, (2) the improvement in the control of corruption, regulatory quality and total governance reduces maternal mortality (3) political stability reduces adult female mortality rate. The study makes the following recommendations based on findings. Governments in the region should strive to develop and sustain an efficient working economic environment in order to attract investment and private sector participation so as to increase employment opportunities thereby leading to improved access to healthcare as well as ensuring the improvement of governance in entirety which precipitates to the reduction in infant and maternal mortality. The fight against corruption should be taken seriously as it is shown that corruption is a major drawback to maternal mortality rate in the region. Ensuring political stability should be given due place in order to reduce adult female mortality rate. The government in the region should ensure an inclusive growth, manpower training and sound education to ensure stability in the political arena, which ensures peace and reduces violence for which women and children are more vulnerable.

It is also important that sound macroeconomic policies should be of topmost priority in order to ensure reduction in inflation rate. Governments of countries in the region should take critical measures to forestall the spread of the HIV as the result shows that it is a cause of mortality in the region. Sensitizations and campaigns against the disease should be scaled up, and subsidization of antiretroviral drugs by governments are desirable so 
as to reduce the burden of the disease on its carriers. Furthermore, governments should strive to improve on the available manpower as the supply of physicans and health personnel are very low compared to what is obtainable in the advanced nations. Doing this will prevent the losses incured, thus, medical tourism and improved service delivery in the society would ultimately address issues around mortality. Lastly, partnerships should be established with international organizations in order to access external resources and funding for women and child health programmes. Non-Government Organizations (NGOs) should be given a peaceful platform in order to pursue their plans and programmes.

\section{References}

Amaz, C., Gaume, V. and Lefevre, M., 2012. The impact of Training on Firm Scrap Rate: A study of Panel Data. [Online] Available at: http://wwwperso.gate.cnrs.fr/polome/Pages20I2_I3/Panel/LE FEVRE_GAUME_AMAZ_rapport.pdf

Asongu, S. and Nwachukwu, J., 2016. The role of Governance in mobile phones for Inclusive Human Development in Sub-Saharan Africa. Technovation, pp. I-13.

Asongu, S. and Odhiambo, N., 2018. Governance and Social Media in African Countries: An Empirical Investigation. Telecommunication Policy.

Asongu, S., Tchamyou, V., Asongu, N. and Tchamyou, N., 2017. Fighting Terrorism in Africa: Evidence from Bundling and Unbundling Institutions. Empirical Economics, pp. |-5I.

Avendano, M., 2012. Correlation or Causation? Income Inequality and Infant Mortality in Fixed Effects Models in the Period 1960-2008 in 34 OECD Countries. Social Science \& Medicine, 75(4), pp. 754-760.

Baek, S. and Yang, D., 2010. Institutional Quality, Capital Flight and Capital Flows. Korean Economic Review, 26(I), pp. I2I-I55.

Baltagi, B., Kao, C. and Peng, B., 2016. Testing Cross-Sectional Correlation in Large Panel Data Models with Serial Correlation. Econometrics, pp. I-24.

Center for Reproductive Rights, 2008. Broken Promises: Human Rights, Accountability and Maternal Death in Nigeria.

Chisumpa, V., Odimegwu, C. and De Wet, N., 2017. Adult Mortality in Sub-Saharan Africa, Zambia: Where do Adults Die?. SSM-Population Health, Volume 3, pp. 227-235.

Deluna, R. and Peralta, T., 20I4. Public Health Expenditures, Income and Health Outcomes in the Philippines. MPRA, pp. I-20.
Ditzen, J., 2016. XTCD2: Stata Module to Test for Weak Cross Sectional Dependence, Boston College Department of Economics.

Driscoll, J. and Kraay, A., 1998. Consistent Covariance Matrix Estimation with Spatial Dependent Data. Review of Economic and Statistics, Volume 80, pp. 549-560.

Emamgholipour, S. and Asemane, Z., 2016. Effect of Governance Indicators on Under-Five Mortality in OECD Nations: Generalised Method of Moments. Electron Physician, 8(I), pp. 1747-I75I.

Fukuyama, F., 2013. What is Governance?. Center for Global Development Working Paper 3I4.

Grossman, M., 1972. On the Concept of Health Capital and the Demand for Health. The Journal of Political Economy, 80(2), pp. 223-255.

Hamal, M. et al., 2018. How does Social Accountability contribute to better Maternal Health Outcomes? A Quantitative study on Perceived Changes with Government and Civil Society Actors in Gujarat, India. BMC Health Service Research, Volume 18.

Hammer, L., Lensink, R. and White, H., 2003. Infant and Child Mortality in Developing Countries: Analysing the Data for Robust Determinants. The Journal of Development Studies, 40(I).

Harrison, K., 2009. The Struggle to Reduce High Maternal Mortality in Nigeria. African Journal of Reproductive Health, 13(3), pp. 9-20.

Hoechle, D., 2007. Robust Standard Errors for Panel Regressions with Cross-Sectional Dependence. The Stata Journal, 7(3), pp. 28I-3I 2 .

Iheonu, C.O., 2019. Governance and Domestic Investment in Africa. Working Papers of the African Governance and Development Institute, Issue 19/00I.

Jolliffe, I., 2002. Principal Component Analysis. 2nd ed. New York: Springer.

Joses, M. and Saidou, P., 2008. Health Challenges in Africa and the way forward. International Archives of Medicine.

Kaufman, D., Kraay, A. and Maztruzzi, M., 2005. Governance Matters III: Governance Indicators for 1996-2002, Washington DC: World Bank.

Kaundjua, M., 2013. The Determinants of the Child Mortality Rate in Rural Namibia. Journal for Studies in Humanities and Social Sciences, 2(I), pp. 34-5I.

Lasker, M. and King, M., 1997. Modified Wald Test for Regression Disturbances. Economic Letters, 56(I), pp. 5-II.

Lin, R., Chien, L., Chen, Y. and Chan, C., 2014. Governance Matters: an Ecological Association between Governance and Child Mortality. International Health, 6(3), pp. 249-257. 
Makuta, I. and O'Hare, B., 20I5. Quality of Governance, Public Spending on Health and Health Status in Sub-Saharan Africa: a Panel Data Regression Analysis. BMC Public Health, Volume 15.

Mogford, L., 2004. Structural Determinants of Child Mortality in Sub Saharan Africa: A Cross-National study of Economic and Social Influences from I 970 to 1997. Social Biology, 5I(3-4).

Mojekwu, J. and Ibekwe, U., 20I2. Maternal Mortality Nigeria: Examination of Intervention Methods. International Journal of Humanities and Social Science, 2(20), pp. I35-149.

Odhiambo, S., Wambugu, A. and Kiriti-Nganga, T., 2015. Has Quality of Governance affected the Effectiveness of Health Expenditure on Adult Health in Sub Saharan Africa. European Scientific Journal, I I (I6), pp. 27|-297.

Omedi, G., 2018. Reversal in Infant Mortality in Kenya based on the type of Place of Residence. African Population Studies, 32(2), pp. 4332-4344.

Opiyo, C. and Sawhney, M., 2014. Determinants of the Recent Rise in Childhood Mortality in SubSaharan Africa: Evidence from Kenya Demographic and Health Survey, 1990-2003. African Population Studies, 28(2), pp. I I82-। I 93.

Pesaran, M., 2015. Testing Weak Cross-Sectional Dependence in Large Panels. Econometric Reviews, 34(6-10), pp. I089-III 7.

Rebeira, M., Grootendorst, P., Coyte, P. and Aguirregabiria, V., 20l7. Does Rising Income
Inequality affect Mortality Rates in Advanced Economies?. Economics: The Open-Access, Open Assessment E-Journal, I I(20I7-16), pp. I-23.

Shay, I. and Say, L., 2007. Maternal Mortality and Maternal Care from 1990 to 2005: Uneven but important gains. Reproductive Health Matters, I5(30), pp. 17-27.

Tchamyou, S., 2017. The role of Knowledge Economy in African Business. Journal of the Knowledge Economy, 8(4), pp. II 89-I 228.

Transparancy International, 2017. Corruption Perceptions Index 2017. [Online] Available at: www.transparency.org/news/feature/corruption perceptions index 2017

Ujah, I. et al., 2005. Factors Contributing to Maternal Mortality in North-Central Nigeria: A Seventeenyear Review. African Journal of Reproductive Health, 9(3), pp. 27-40.

UNAIDS, 2018. People Living with HIV. [Online] Available at: www.unaids.org/en/keywords/people-living-hiv

Wooldridge, J., 2002. Econometric Analysis of Cross Section and Panel Data. Massachusetts: MIT Press.

World Bank, 2017. World Development Indicators. www.datacatalog.worldbank.org/dataset/worlddevelopment-indicators

World Bank, 2017. World Governance Indicators. www.datacatalog.worldbank.org/dataset/worldwi de-governance-indicators. 